\title{
Informal care provision across multiple generations in China
}

\author{
Jane Falkingham $^{1 \star}$, Maria Evandrou ${ }^{1,2}$, Min Qin ${ }^{1,2}$ and Athina Vlachantoni ${ }^{1,2}$ \\ ${ }^{1}$ ESRC Centre for Population Change, University of Southampton, Southampton, UK and ${ }^{2}$ Centre for \\ Research on Ageing, University of Southampton, Southampton, UK \\ ${ }^{*}$ Corresponding author. Email: j.c.falkingham@soton.ac.uk
}

(Accepted 1 March 2019; first published online 25 April 2019)

\begin{abstract}
With increasing life expectancy, changes in family structure and, most recently, the relaxation of the hitherto strict family planning policies, understanding how mid-life individuals support multiple generations, particularly their older parents and younger grandchildren, is of increasing research and policy significance in China. This paper analyses data from the 2011 China Health and Retirement Longitudinal Study (CHARLS) to examine the characteristics of Chinese mid-life individuals aged 45-64 who are potentially being 'sandwiched' between providing care to older parents/parents-in-law and/or younger grandchildren (under age 16). Binary logistic and multinomial regression models shed light on the factors associated with providing support to one generation or multiple generations. The results highlight that amongst the Chinese mid-life sandwich generation, 58 per cent only provide care to their young grandchildren, 23 per cent only provide care to their parents/parents-in-law, whilst 15 per cent are simultaneously supporting both generations. Rather than acting as competing demands upon the mid-lifers' time, the multivariate analysis provides evidence that the provision of intergenerational care is complementary, with caring for grandchildren increasing the probability of also supporting one's parents/parents-in-law, and vice versa. However, an increase in the number of younger grandchildren has a negative impact on the care provided to older parents/parents-in-law, indicating that at higher care intensities there may be competing demands across the generations.
\end{abstract}

Keywords: informal care-giving; intergenerational relationship; sandwich generation

\section{Introduction}

In contemporary China, the provision of care for older parents/parents-in-law remains a common and normative experience for adult children (Silverstein et al., 2006; Hu and Ma, 2018). The same social norms and traditional family structures also mean that many Chinese grandparents expect to provide care for their young grandchildren (Chen et al., 2011). With improvements in mortality, more

(C) Cambridge University Press 2019. This is an Open Access article, distributed under the terms of the Creative Commons Attribution licence (http://creativecommons.org/licenses/by/4.0/), which permits unrestricted re-use, distribution, and reproduction in any medium, provided the original work is properly cited. 
people in China are surviving to older ages, and an increasing number of people in their fifties and early sixties can now expect to have one or more surviving parents or parents-in-law. At the same time, increasing migration has resulted in more people caring for their 'left behind' grandchild as their adult children find work in the towns and cities, a trend which may be further exacerbated in future by the recent relaxation of hitherto strict family planning policies. Thus, a growing number of individuals in China face the possibility in mid-life of being 'sandwiched' between the provision of care to their own older parents/parents-in-law and also to their younger grandchildren. Understanding how this so-called 'sandwich generation' divides their resources in terms of time between the care of older and younger generations and other activities, including paid employment, is particularly pertinent in a context such as China, where the state remains predominantly dependent on the family for the delivery of care for older people and infant/toddlers (Zimmer and Kwong, 2003; Cong and Silverstein, 2012), and where the government has recently indicated that it plans to increase the retirement age (Chen and Groenewold, 2017), with the result that in the near future, even more individuals in their fifties and early sixties may be faced with the need to juggle work and family responsibilities.

\section{Theoretical background and the Chinese context}

Previous research, mainly conducted within the context of contemporary western societies, on understanding patterns of informal care provision to multiple generations has given rise to a range of inter-related theoretical frameworks, most prominent of which are the concepts of 'family solidarity', 'family adaptive strategy' and the lifecourse perspective of 'linked lives'. The theory of intergenerational family solidarity, first outlined by Bengston and Roberts (1991), posits six dimensions of intergenerational family cohesion, i.e. association, affection, consensus, resource sharing, opportunity for interaction and the strength of familism norms, that define the degree to which a child is likely to support a parent or vice versa. Here, normative solidarity and responsibility towards family members influence the support provided to both older parents/parents-in-law and grandchildren; and functional solidarity then reflects the degree of helping and exchanges of resources. Previous studies using such a framework have highlighted the role of filial responsibility in the provision of support to parents (Korinek et al., 2011), whilst others have demonstrated the positive effect of perceived family obligations on grandparents' engagement in grandchildren's care (Chen et al., 2011). Adopting this theoretical framework implies that in a context where filial obligation is the social norm, mid-life sandwich individuals may find themselves obliged to provide care to multiple generations simultaneously.

Alternatively, the theory of the family adaptive strategy, proposed by Moen and Wethington (1992), considers the family as an active participant in the larger society, an actor responding to external constraints and opportunities. Viewed from this perspective, the provision of informal care to older parents/parents-in-law and/or young grandchildren may be understood in terms of household members adaptively responding to external disadvantages and advantages, such as women's (daughters/daughters-in-law) job participation, ill health of older parents/ 
parents-in-law and a lack of formal social care available to either generation, for the overall benefit of the household (Yan, 2003). Thirdly, lifecourse models place intergenerational exchanges in a wider historical and social context. Changes in the broader socio-demographic, institutional and economic environment can lead to fluctuations in the family resources and needs, and in turn, result in informal care provision aimed at reducing the gap between the two. Care-giving from midlife sandwich individuals to older parents/parents-in-law and/or grandchildren can be seen as being embedded in a network of family ties, reflecting the lifecourse perspective of the 'linked lives' where 'lives are lived interdependently, and social and historical influences are expressed through this network of shared relationships' (Elder, 1998: 4).

In traditional Chinese society, intergenerational exchanges are guided by the social norm of filial piety. Under such a norm, parents command absolute obedience from their adult children, and children are obligated to prioritise their parents above all other responsibilities. Previous empirical research suggests that traditional norms governing intergenerational relations in China have largely persisted despite the recent socio-economic transformation of the country which has been accompanied by rapid economic growth, increasing incomes and greater independence (Zimmer and Kwong, 2003), with co-residence of older parents with an adult child remaining the key mechanism through which intergenerational support is maintained (Zhang, 2004; Li et al., 2005; Korinek et al., 2011), and with those not co-residing commonly relying on an adult child living nearby. This obligation that children should take care of their parents when in need has even been formalised into the Chinese constitution (National People's Congress of PRC, 2004, 2013).

There is no parallel formal duty of grandparents to provide support to grandchildren in conventional Chinese culture. However, in contemporary rural and urban China, it has become increasingly common for grandparents to play a major caregiving role (Chen et al., 2011). In part this reflects the lack of options around early childhood care; with only sporadic formal public services available, especially for infants and toddlers aged $0-3$. This, combined with high employment rates among women, a relatively short period of maternity leave (three to six months after the birth) and recent substantial rural to urban migration, has meant that Chinese grandparents have become more involved in grandchild care, a trend further supported by the relatively young state retirement age (50 or 55 for women and 60 for men) (Corter et al., 2006; Guo et al., 2009; Chen and Liu, 2012). Child care provided by grandparents relieves the young parents' care burden, thereby enabling them, especially daughters/daughters-in-law, to continue to participate in paid economic activities. Such a family 'adaptive strategy' can be viewed to maximise the wellbeing of the whole family. Some researchers have argued that this phenomenon also points to a change in the construct of filial piety, moving from the traditional uni-directional flow (adult children to older parents) towards a new norm of reciprocity, where grandparents taking care of grandchildren can be considered to be part of a bargaining strategy which guarantees them old-age support later on (Croll, 2006; Cong and Silverstein, 2012). 


\section{The 'sandwich generation'}

The concept of the sandwich generation was initially introduced by Miller in the 1980 s to describe middle-aged care-givers 'sandwiched' between their parents and children (Miller, 1981). Since then, the use of the term has expanded as improvements in longevity have increased the number of surviving generations within families and care-giving roles have broadened (Rubin and White-Means, 2009; Friedman et al., 2015; Vlachantoni et al., 2019). Today the term sandwich generation can be used to describe those in their fifties and sixties who are sandwiched between ageing parents, adult children and grandchildren, or alternatively those in their thirties or forties with young children, ageing parents as well as their grandparents (Abramson, 2015). The extent of being sandwiched between two, three or even four generations and actually providing care to such generations varies considerably, depending on the definition and target age groups. One study reported that just 9 per cent of women aged 45-56 in the United States of America (USA) simultaneously provided care for their parent and dependent children (Pierett, 2006). In contrast, Friedman et al. (2015) found that around 30 per cent of people aged 35-75 were providing time or money to parents and children (including adult children aged 18 and over). A study comparing data from the USA and the United Kingdom from the 1980s and 1990s defined the sandwich generation as those aged 55-69 with at least one child and one parent alive, and found that 30 per cent of such individuals were helping both generations either with child care, non-financial support or financial support (Grundy and Henretta, 2006). More recently, a report using 2009-2011 data from Ireland found that 31 per cent of women aged between 50 and 69 were sandwiched between their parents and children, and 60 per cent of those were simultaneously providing grandchild care and non-financial help to their own parents (McGarrigle and Kenny, 2013).

Moving beyond the prevalence of multiple role occupancy, previous research has explored how juggling multiple roles influenced care-giving activities, labour force participation and health/wellbeing (Evandrou and Glaser, 2002; Evandrou et al., 2002; Glaser et al., 2006; Gomez-Leon et al., 2017). A key question is whether the care provision for one generation competes with care provision for a different generation, or whether they are complementary. Previous studies have found supportive evidence for the 'solidarity hypothesis' against the 'competing demand hypothesis', with helping one generation being positively associated with helping another generation (Grundy and Henretta, 2006; Fingerman et al., 2010). However, the study by Grundy and Henretta (2006) also found that care towards one's parents declines when there is a higher number of members from the younger generation alive.

All of the studies discussed above were conducted in developed countries. To the best of our knowledge, to date there have been no similar studies of the 'sandwich generation' in China, a middle-income country where the social, economic and political contexts are different from those of developed countries and where care provision to family members in need, both for older parents/parents-in-law and young grandchildren, almost entirely rely on the family due to the weak/lack of a developed social care system and the strong cultural traditions of extended kin. This 
study therefore aims to fill this research gap by providing the first insights into the prevalence and characteristics of the sandwich generation in China using recently available data from a nationally representative survey, the China Health and Retirement Longitudinal Study (CHARLS). The sandwich generation is defined here as mid-life individuals aged 45-64 'sandwiched' between multiple generations, i.e. having at least one living parent/parent-in-law and one grandchild under age 16.

The paper makes three unique contributions: (a) it provides new evidence on the profile of the sandwich generation in China; (b) it explores whether transfers from adults in late mid-life to elderly parents/parents-in-law are positively or negatively associated with transfers to younger grandchildren, and vice versa; and (c) amongst the sandwich generation, i.e. only those potentially providing care to multiple generations, it examines the socio-demographic characteristics associated with caring for multiple generations from the characteristics among those caring for only one generation, or none. The findings from the research are of direct relevance for policy makers and practitioners in China concerned with the provision of longterm care to its ageing population.

\section{Data and method}

The data in this study are drawn from CHARLS, conducted by the National School of Development at Peking University. Using a stratified multi-stage 'probability proportional to size' random sampling method, the CHARLS survey was conducted nationwide in 2011-2012, covering 28 out of 31 provinces, 150 districts/counties and 450 communities/villages (Zhao et al., 2013). One person per household aged 45 years or older was selected, and they and their spouse were interviewed face-to-face by trained interviewers using structured questionnaires. Signed informed consent was obtained from all participants by the CHARLS survey team before the data were collected (Zhao et al., 2013). We chose to analyse the CHARLS baseline 2011 data rather than the more recent data from 2015 CHARLS Wave 4 because of the concerns of non-random sample attrition during the longitudinal follow-up survey. Although the CHARLS has adopted a refresh sample to address attrition and maintain overall sample size, it is unclear whether this supplementation completely captures the features of care-giving behaviour and associated characteristics, especially if those respondents with high-intensity caregiving responsibilities are disproportionately lost to follow-up.

\section{Identifying the sandwich generation}

In order to address the question of how individuals support multiple generations (parents/parents-in-law and grandchildren) in China, the sample of interest was restricted to those respondents aged between 45 and 64 . The rationale for this age range selection is that age 45 is likely to be the lower boundary of the age at which people become a grandparent, since the average marriage age in 1990 was around 23 (Lu and Wang, 2013); conversely age 64 is likely to be approaching the upper age limit at which significant numbers of individuals have a surviving parent alive, given that the life expectancy in 2010 was around 75 years (National Bureau of Statistics of PRC, 2012). Respondents in the two decades of 
mid-life between 45 and 64 are thought to be the most likely to have at least one surviving parent/parent-in-law and grandchild. Thus, our analytical sample comprises all individuals who were interviewed at age 45-64, and faced the possibility of potentially supporting multiple generations (i.e. having at least one parent/ parent-in-law alive and having at least one grandchild under age 16), with the provision of grandchild-care being understood as the indirect provision of support by the respondent towards their own child. The final sub-sample was 4,103 individuals (Table 1).

\section{Provision of support to parents/parents-in-law}

All respondents were asked whether over the past year they or their spouse had spent time taking care of their parents or parents-in-law. The question on the support provision towards the respondent's parents/parents-in-law captured both basic and instrumental support:

- Did you/your spouse take care of your parents or parents-in-law during the last year in assisting them in their daily activities or other activities (e.g. household chores, meal preparation, laundry, going out, grocery shopping, financial management, etc.)?

The survey also collected information on how much time respondents and their spouse spent for the care provision to each parent/parent-in-law, allowing the construction of a variable measuring the intensity of caring for each parent/parent-in-law:

- Approximately how many weeks and how many hours per week did you yourself spend last year taking care of your parents or parents-in-law?

- Approximately how many weeks and how many hours per week did your spouse spend last year taking care of your parents or parents-in-law?

All answers of respondents and their spouses were separately recoded. Responses to these questions were used to compute a care provision intensity variable capturing the average weekly hours of care to parents/parents-in-law with four categories: not caring, $\leqslant 9$ hours a week, 10-19 hours a week and 20+ hours a week.

\section{Provision of grandchild care}

Respondents were asked:

- Did you/your spouse spend any time taking care of your grandchildren under age 16 last year? For which child's children did you/your spouse provide care?

The frequency and intensity of grandchild care of the respondent and their spouse were then identified using the following questions:

- Approximately how many weeks and how many hours per week did you spend last year taking care of this child's children? Approximately how many weeks and how many hours per week did your spouse spend last year taking care of this child's children? 
Table 1. Percentage of respondents aged $45-64$ by sex and whether they have at least one parent/ parent-in-law and younger grandchild alive

\begin{tabular}{lccc}
\hline & Male & Female & Total \\
& & Percentages (N) & \\
\hline $\begin{array}{l}\text { No parent/parent-in-law alive or younger } \\
\text { grandchildren }\end{array}$ & $11.6(703)$ & $10.4(673)$ & $11.0(1,376)$ \\
$\begin{array}{l}\text { At least one parent/parent-in-law alive, no } \\
\text { younger grandchildren }\end{array}$ & $26.6(1,618)$ & $22.9(1,486)$ & $24.7(3,104)$ \\
$\begin{array}{l}\text { At least one younger grandchild, no } \\
\text { parent/parent-in-law alive }\end{array}$ & $29.1(1,765)$ & $34.0(2,204)$ & $31.6(3,969)$ \\
$\begin{array}{l}\text { At least one parent/parent-in-law and } \\
\text { grandchild alive (sandwich individuals) }\end{array}$ & $32.7(1,987)$ & $32.7(2,116)$ & $32.7(4,103)$ \\
\hline \begin{tabular}{l} 
Total \\
\hline
\end{tabular} & $100.0(6,073)$ & $100.0(6,479)$ & $100.0(12,552)$ \\
\hline
\end{tabular}

Note: $\mathrm{N}=12,552$.

Source: Authors' own analysis, China Health and Retirement Longitudinal Study (CHARLS Wave 1).

Again, all answers of respondents and their spouses were separately recoded. Responses to these questions were used to compute a care provision intensity variable, which was re-coded into a categorical variable with the same categories as those for the intensity of parental support: i.e. not caring, $\leqslant 9$ hours a week, 1019 hours a week and $20+$ hours a week.

\section{Key explanatory variables}

Previous research has highlighted that the need for care amongst parents/ parents-in-law and/or younger grandchildren are key factors associated with informal care provision. Unfortunately, the CHARLS did not collect information on the need for support (e.g. health status) amongst the respondents' parents/ parents-in-law or young grandchildren at Wave 1, thus it is not possible to control directly for need. Other studies have used the number of grandchildren under age 16 and surviving parents/parents-in-law as a proxy for need (Grundy and Henretta, 2006) or information on the co-residence with parents/parents-in-law or young grandchildren (Korinek et al., 2011). Both of these variables were included here. Based on the existing literature, other socio-economic characteristics associated with informal care provision were also included as covariates to account for observable heterogeneity: these included marital status, education, working status, income, household wealth index and urban/rural residence (Fingerman et al., 2010; McGarrigle and Kenny, 2013).

\section{Analytical strategy and dealing with missing values of variables}

The analysis was carried out in a staged approach. Bi-variate analysis was used to describe the profile of the sandwich generation in China, before focusing on their care provision and the intensity of the support. Logistic regression was then applied to investigate the association between supporting one generation and supporting the other, controlling for several demographic and socio-economic covariates. 
Finally, multinomial logistic regression was used to examine how the characteristics of care-givers towards multiple generations differ from those among individuals who care for only one generation. The significance levels reported in the results are $p<0.05\left(^{*}\right), p<0.01\left(^{* *}\right)$ and $\left.p<0.001^{* * *}\right)$. The analyses were conducted using Stata version 15 .

From the initial sample of 4,103, 72 respondents were excluded from the analysis of informal care provision because of missing values on the yes/no response of care provision to either parents/parents-in-law or younger grandchildren, resulting in an analytical sample size of 4,031. A number of respondents also had missing data on some of the other key variables of interest, including weekly hours of care provision to parents/in-laws $(\mathrm{N}=207)$, weekly hours of care provision to grandchildren $(\mathrm{N}=$ $796)$, marital status $(\mathrm{N}=2)$, disability $(\mathrm{N}=5)$, working status $(\mathrm{N}=15)$, education $(\mathrm{N}=4)$, income $(\mathrm{N}=24)$ and household wealth quintile $(\mathrm{N}=34)$. After excluding all cases with missing data on any of the control variables, the study sample size is potentially reduced to 3,980 . Given this, a decision was made to impute the missing values for care provision intensity (categorical variables) to both grandchildren and to parents/parents-in-law, together with marital status, disability, working status, education, income and household wealth quintile index using multivariate imputation by chained equations ${ }^{1}$ based on age, gender, chronic illness, number of parents/parents-in-law, number of young grandchildren, co-residence with grandchildren, co-residence with parents/parents in-law and urban/rural residence.

For the logistic regression, the models were initially run considering care provision with only yes/no response as the dependent variable, with a sample size of 4,031 . The models for intensity of care were then run on two alternative samples, the first excluding all cases with missing values $(\mathrm{N}=3,980)$ and then including the imputed variables $(\mathrm{N}=4,031)$.

\section{Results}

Table 1 shows the prevalence of the sandwich generation in the overall sample. Almost one-third (32.7\%) of the respondents aged 45-64 have both at least one parent/parent-in-law and a younger grandchild alive, and thus may be called upon to provide support towards both generations. One-third (31.6\%) have a grandchild but no surviving parent/parent-in-law and a further 11.0 per cent do not have relatives from either generation. A quarter $(24.7 \%)$ have at least one parent/parent-in-law alive but no grandchildren.

Figure 1 provides further insight into the generational structure within the respondents' family, focusing on the number of younger grandchildren and parents/parents-in-law for men and women. About two-thirds of all mid-life Chinese men and women (62 and 67\%) have at least one younger grandchild. Over one-in-four respondents have one younger grandchild, and 10 per cent of men and 12 per cent of women have four or more younger grandchildren. More than half men and women (59 and 56\%) have at least one parent/parent-in-law alive. Over half of men and women have at least one parent/parent in-law alive. The majority of these had only one surviving parent/parent in law and just 3 per cent women and 2 per cent men had four parents/parents in-law alive. 


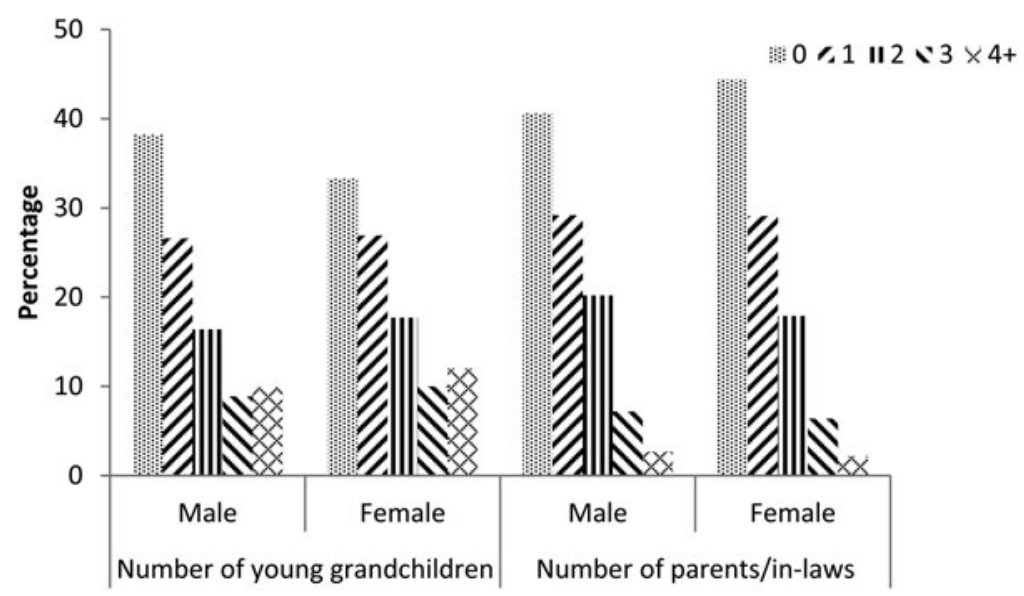

Figure 1. Percentage of men and women aged $45-64$ by number of younger grandchildren and parents/ parents-in-law. Note: $\mathrm{N}=12,552$

\section{Exploring the characteristics of 'sandwiched' individuals}

Table 2 shows the characteristics of all respondents aged 45-64, distinguishing by sex and whether the respondent is potentially being 'sandwiched', using the same typology as Table 1. For both men and women, sandwiched individuals are more likely to be in the age groups 50-59 and to be currently married than others. There are significant differences in the socio-economic profile of each group. Mid-life men and women with no surviving parents but with younger grandchildren tend to be less educated and in the lower quintile of the household wealth index compared with any other group. Conversely, those with parents/ parents-in-law alive but no grandchildren are more likely to have a degree or higher education and be in the highest quintile of the household wealth index (Table 2). This can be explained by socio-economic gradients in the age at first birth and in mortality, both of which affect the likelihood of simultaneously having surviving parents and grandchildren.

The next section focuses on respondents who could potentially be a carer for multiple generations in order to investigate how their care provision is allocated between different generations. The analytical sample here is limited to those who have at least one younger grandchild and parent/parent-in-law, and who have no missing values on the yes/no question regarding care provision either for parents/parents-in-law or younger grandchildren. The total sample size is 4,031.

Amongst those potentially at risk of caring for multiple generations simultaneously, just 15 per cent of respondents report that they are providing informal care to both parents/parents-in-law and younger grandchildren. A further 43 per cent are caring for young grandchildren only and 8 per cent for parents/ parents-in-law only (Table 3). Overall, 58 per cent of the sandwich generation is providing care to younger grandchildren and 23 per cent is providing support to older parents/parents-in-law. Compared to others within the sandwich generation, 
Table 2. Respondents' characteristics by typology of surviving generations

\begin{tabular}{|c|c|c|c|c|c|c|c|c|}
\hline & \multicolumn{2}{|c|}{ Sandwiched } & \multicolumn{2}{|c|}{$\begin{array}{l}\text { Parents, no younger } \\
\text { grandchild }\end{array}$} & \multicolumn{2}{|c|}{$\begin{array}{l}\text { Younger } \\
\text { grandchildren, no } \\
\text { parents }\end{array}$} & \multicolumn{2}{|c|}{$\begin{array}{l}\text { No parents or younger } \\
\text { grandchildren }\end{array}$} \\
\hline & Male & Female & Male & Female & Male & Female & Male & Female \\
\hline & \multicolumn{8}{|c|}{ Percentages } \\
\hline \multicolumn{9}{|l|}{ Age group: } \\
\hline $55-59$ & 35.5 & 32.0 & 13.3 & 8.4 & 34.4 & 37.6 & 26.5 & 24.5 \\
\hline $60-64$ & 20.3 & 14.8 & 4.5 & 4.0 & 46.1 & 38.8 & 20.1 & 22.1 \\
\hline \multicolumn{9}{|l|}{ Marital status: } \\
\hline Currently married & 97.3 & 94.5 & 97.5 & 95.4 & 93.0 & 88.5 & 89.2 & 88.5 \\
\hline Yes & 45.3 & 49.5 & 38.6 & 40.8 & 44.2 & 53.6 & 42.7 & 49.5 \\
\hline \multicolumn{9}{|l|}{ Whether disabled: } \\
\hline No & 84.8 & 87.8 & 88.7 & 91.7 & 81.1 & 84.4 & 80.5 & 86.2 \\
\hline Yes & 15.2 & 12.2 & 11.3 & 8.3 & 18.9 & 15.6 & 19.5 & 13.8 \\
\hline \multicolumn{9}{|l|}{ Working status: } \\
\hline Not working & 15.2 & 29.7 & 12.8 & 23.5 & 21.0 & 34.6 & 19.5 & 35.6 \\
\hline
\end{tabular}


Table 2. (Continued.)

\begin{tabular}{|c|c|c|c|c|c|c|c|c|}
\hline & \multicolumn{2}{|c|}{ Sandwiched } & \multicolumn{2}{|c|}{$\begin{array}{l}\text { Parents, no younger } \\
\text { grandchild }\end{array}$} & \multicolumn{2}{|c|}{$\begin{array}{c}\text { Younger } \\
\text { grandchildren, no } \\
\text { parents }\end{array}$} & \multicolumn{2}{|c|}{$\begin{array}{l}\text { No parents or younger } \\
\text { grandchildren }\end{array}$} \\
\hline & Male & Female & Male & Female & Male & Female & Male & Female \\
\hline Agricultural work & 64.0 & 60.6 & 49.8 & 50.1 & 65.2 & 60.1 & 54.7 & 45.3 \\
\hline Non-agricultural work & 20.8 & 9.7 & 37.4 & 26.4 & 13.9 & 5.3 & 25.8 & 19.1 \\
\hline \multicolumn{9}{|l|}{ Education: } \\
\hline No schooling & 8.8 & 37.8 & 4.0 & 16.5 & 10.7 & 44.1 & 10.7 & 26.9 \\
\hline Primary school & 43.6 & 38.5 & 28.4 & 30.6 & 54.2 & 40.4 & 37.9 & 34.8 \\
\hline Secondary and above & 47.6 & 23.8 & 67.6 & 52.9 & 35.1 & 15.6 & 51.4 & 38.4 \\
\hline \multicolumn{9}{|l|}{ Urban/rural: } \\
\hline Rural & 81.1 & 79.3 & 67.1 & 65.3 & 83.1 & 81.8 & 70.0 & 62.0 \\
\hline Urban & 18.9 & 20.7 & 32.9 & 34.7 & 16.9 & 18.2 & 30.0 & 38.0 \\
\hline \multicolumn{9}{|l|}{ Income: } \\
\hline No & 59.9 & 79.0 & 49.8 & 63.3 & 62.6 & 78.0 & 59.4 & 66.2 \\
\hline Yes & 40.1 & 21.0 & 50.2 & 36.7 & 37.4 & 22.0 & 40.6 & 33.8 \\
\hline \multicolumn{9}{|c|}{ Household wealth quintile index: } \\
\hline First & 14.1 & 14.1 & 10.4 & 9.6 & 19.3 & 20.3 & 24.6 & 15.8 \\
\hline Second & 18.7 & 19.1 & 15.0 & 13.0 & 23.9 & 23.7 & 18.5 & 19.8 \\
\hline Third & 22.9 & 22.4 & 21.1 & 21.1 & 21.6 & 21.5 & 16.8 & 18.2 \\
\hline Fourth & 22.7 & 23.1 & 21.3 & 21.1 & 19.9 & 19.0 & 19.8 & 24.3 \\
\hline Fifth & 21.6 & 21.3 & 32.2 & 35.2 & 15.4 & 15.6 & 20.3 & 21.8 \\
\hline
\end{tabular}

Source: Authors' own analysis, China Health and Retirement Longitudinal Study (CHARLS Wave 1). 
Table 3. Profile of characteristics by caring typology among respondents aged 45-64 at risk of caring for both generations (sandwich generation)

\begin{tabular}{|c|c|c|c|c|c|}
\hline & \multicolumn{4}{|c|}{ Caring typology } & \multirow[b]{2}{*}{$p$} \\
\hline & $\begin{array}{c}\text { Both } \\
\text { generations }\end{array}$ & $\begin{array}{c}\text { Younger } \\
\text { grandchildren } \\
\text { only }\end{array}$ & $\begin{array}{l}\text { Parents/ } \\
\text { parents-in-law } \\
\text { only }\end{array}$ & None & \\
\hline \multicolumn{6}{|c|}{ Percentages } \\
\hline Total & 15.2 & 43.2 & 7.5 & 34.0 & \\
\hline Age group: & & & & & $\star \star \star *$ \\
\hline $45-49$ & 23.5 & 19.3 & 27.6 & 25.4 & \\
\hline $50-54$ & 29.2 & 28.4 & 24.3 & 24.1 & \\
\hline $55-59$ & 34.2 & 34.6 & 30.6 & 32.4 & \\
\hline $60-64$ & 13.2 & 17.6 & 17.4 & 18.1 & \\
\hline \multicolumn{6}{|l|}{ Gender: } \\
\hline Male & 49.0 & 47.7 & 49.0 & 49.2 & \\
\hline Female & 51.0 & 52.3 & 51.0 & 50.8 & \\
\hline \multicolumn{6}{|l|}{ Marital status: } \\
\hline $\begin{array}{l}\text { Currently } \\
\text { married }\end{array}$ & 98.0 & 95.6 & 94.4 & 95.4 & * \\
\hline $\begin{array}{l}\text { Not currently } \\
\text { married }\end{array}$ & 2.0 & 4.4 & 5.6 & 4.6 & \\
\hline \multicolumn{6}{|l|}{$\begin{array}{l}\text { Reporting chronic } \\
\text { illness: }\end{array}$} \\
\hline No & 51.0 & 52.4 & 51.0 & 53.6 & \\
\hline Yes & 49.0 & 47.6 & 49.0 & 46.4 & \\
\hline \multicolumn{6}{|l|}{ Whether disabled } \\
\hline No & 86.6 & 86.0 & 84.8 & 87.1 & \\
\hline Yes & 13.4 & 14.0 & 15.2 & 12.9 & \\
\hline \multicolumn{6}{|l|}{$\begin{array}{l}\text { Number of } \\
\text { parents/in-laws: }\end{array}$} \\
\hline 1 & 52.8 & 58.6 & 57.9 & 59.7 & \\
\hline 2 & 35.0 & 30.4 & 32.6 & 29.0 & \\
\hline 3 & 8.6 & 8.6 & 6.9 & 8.5 & \\
\hline 4 & 3.6 & 2.4 & 2.6 & 2.8 & \\
\hline \multicolumn{6}{|l|}{$\begin{array}{l}\text { Number of } \\
\text { younger } \\
\text { grandchildren: }\end{array}$} \\
\hline 1 & 49.2 & 40.6 & 52.3 & 48.9 & 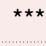 \\
\hline 2 & 24.6 & 29.2 & 24.3 & 26.2 & \\
\hline
\end{tabular}


Table 3. (Continued.)

\begin{tabular}{|c|c|c|c|c|c|}
\hline & \multicolumn{4}{|c|}{ Caring typology } & \multirow[b]{2}{*}{$p$} \\
\hline & $\begin{array}{c}\text { Both } \\
\text { generations }\end{array}$ & $\begin{array}{c}\text { Younger } \\
\text { grandchildren } \\
\text { only }\end{array}$ & $\begin{array}{c}\text { Parents/ } \\
\text { parents-in-law } \\
\text { only }\end{array}$ & None & \\
\hline 3 & 13.4 & 13.0 & 8.2 & 12.3 & \\
\hline $4+$ & 12.9 & 17.2 & 15.1 & 12.6 & \\
\hline $\begin{array}{l}\text { Co-residence with } \\
\text { grandchild(ren): }\end{array}$ & & & & & $\star \star \star$ \\
\hline No & 37.1 & 26.3 & 82.6 & 75.7 & \\
\hline Yes & 62.9 & 73.7 & 17.4 & 24.3 & \\
\hline \multicolumn{6}{|l|}{$\begin{array}{l}\text { Co-residence with } \\
\text { parents/in-laws: }\end{array}$} \\
\hline No & 87.5 & 96.6 & 88.8 & 96.0 & $\star \star \star$ \\
\hline Yes & 12.5 & 3.4 & 11.2 & 4.0 & \\
\hline \multicolumn{6}{|l|}{ Working status: } \\
\hline Not working & 19.2 & 24.3 & 20.8 & 22.5 & \\
\hline $\begin{array}{l}\text { Agricultural } \\
\text { work }\end{array}$ & 63.8 & 61.2 & 63.7 & 62.6 & \\
\hline $\begin{array}{l}\text { Non-agricultural } \\
\text { work }\end{array}$ & 17.0 & 14.5 & 15.5 & 14.9 & \\
\hline \multicolumn{6}{|l|}{ Education: } \\
\hline No schooling & 23.5 & 24.4 & 19.1 & 23.2 & $\star \star$ \\
\hline Primary school & 34.7 & 41.8 & 42.4 & 42.6 & \\
\hline $\begin{array}{l}\text { Secondary and } \\
\text { above }\end{array}$ & 41.8 & 33.8 & 38.5 & 34.3 & \\
\hline \multicolumn{6}{|l|}{ Urban/rural: } \\
\hline Rural & 81.6 & 76.2 & 83.6 & 83.1 & $\star \star \star$ \\
\hline Urban & 18.4 & 23.8 & 16.4 & 16.9 & \\
\hline \multicolumn{6}{|l|}{ Income: } \\
\hline No & 68.8 & 70.1 & 64.4 & 71.0 & \\
\hline Yes & 31.2 & 29.9 & 35.6 & 29.0 & \\
\hline \multicolumn{6}{|l|}{$\begin{array}{l}\text { Household } \\
\text { wealth quintile } \\
\text { index: }\end{array}$} \\
\hline First & 9.8 & 11.2 & 9.5 & 20.1 & $\star \star \star$ \\
\hline Second & 20.2 & 15.3 & 24.0 & 21.9 & \\
\hline Third & 19.3 & 24.3 & 25.7 & 21.2 & \\
\hline
\end{tabular}


Table 3. (Continued.)

\begin{tabular}{lccccc}
\hline & \multicolumn{4}{c}{ Caring typology } \\
\cline { 2 - 5 } & $\begin{array}{c}\text { Both } \\
\text { generations }\end{array}$ & $\begin{array}{c}\text { Younger } \\
\text { grandchildren } \\
\text { only }\end{array}$ & $\begin{array}{c}\text { Parents/ } \\
\text { parents-in-law } \\
\text { only }\end{array}$ & None & $p$ \\
\hline Fourth & 24.3 & 23.9 & 21.7 & 21.1 & \\
\hline Fifth & 26.4 & 25.3 & 19.1 & 15.7 \\
\hline
\end{tabular}

Note: $\mathrm{N}=4,031$.

Source: Authors' own analysis, China Health and Retirement Longitudinal Study (CHARLS Wave 1).

Significance levels: ${ }^{*} p<0.05,{ }^{\star *} p<0.01,{ }^{\star \star *} p<0.001$.

those who are providing care to both generations are more likely to be aged 50-59, to be currently married, co-residing with parents/parents-in-law, and have a relatively high education and a relatively higher household wealth quintile index. Women make up a higher proportion of the mid-life sandwich generation than men, but there is no significant difference across the care typologies.

In terms of the intensity of care provision, around 20 per cent of the sample had a missing value for time spent with their young grandchildren and 5 per cent had a missing value on time spent caring for parents/parents-in-law. Following imputation, 36 per cent of the sandwich generation provided care to young grandchildren for more than 20 hours per week and 7 per cent provided care to parents/ parents-in-law for more than 20 hours per week (data not shown).

\section{Competing demands from younger and older generations}

A key question is whether caring for one generation increases or decreases the likelihood of caring for the other, controlling for other factors. Table 4 illustrates the bi-variate association between caring for parents/parents-in-law and caring for young grandchildren. It shows that caring for parents/parents-in-law increases the chance of caring for grandchildren and vice versa.

The results of two separate models are presented in Table 5. Model 1 shows the odds of caring for grandchildren, controlling for the care provision (yes/no response) to parents/parents-in-law whilst Model 2 shows the odds of caring for parents/parents-in-law, controlling for the care provision (yes/no response) to grandchildren. The results highlight that caring for grandchildren is positively associated with caring for one's parents/parents-in-law and vice versa, with the odds of caring for one generation being twice as likely if you are also caring for the other generation, even after controlling for other factors including co-residence and number of surviving members of the generation - both strong proxies for 'need'.

Table 6 presents the logistic regression model results using the caring intensity variable following the chained multiple imputations. Again, it confirms the complementary nature of care provision, showing that the higher the intensity of care towards one's parents/parents-in-law, the higher the likelihood of caring for younger grandchildren and vice versa. Compared to non-carers, the provision of 20 hours or more of care per week to one's parents/parents-in-law nearly trebles 
Table 4. Percentage of respondents aged 45-64 caring for grandchildren and/or parents or parents-in-law

\begin{tabular}{|c|c|c|c|c|}
\hline & \multicolumn{2}{|c|}{ Caring for grandchildren } & \multicolumn{2}{|c|}{$\begin{array}{l}\text { Caring for parents/ } \\
\text { parents-in-law }\end{array}$} \\
\hline & Not caring & Caring & Not caring & Caring \\
\hline \multicolumn{5}{|c|}{ Caring for parents/parents-in-law: } \\
\hline Not caring & 81.9 & 73.9 & & \\
\hline Caring & 18.1 & 26.1 & & \\
\hline Total & 100.0 & 100.0 & & \\
\hline $\mathrm{N}$ & 1,676 & 2,355 & & \\
\hline$p$ & \multicolumn{2}{|c|}{$<0.000$} & & \\
\hline \multicolumn{5}{|c|}{ Caring for grandchildren: } \\
\hline Not caring & & & 44.1 & 33.1 \\
\hline Caring & & & 55.9 & 66.9 \\
\hline Total & & & 100.0 & 100.0 \\
\hline $\mathrm{N}$ & & & 3,113 & 918 \\
\hline$p$ & & & \multicolumn{2}{|c|}{$<0.000$} \\
\hline
\end{tabular}

Note: $\mathrm{N}=4,031$.

Source: Authors' own analysis, China Health and Retirement Longitudinal Study (CHARLS Wave 1).

the chances of caring for their grandchildren (odds ratio $=2.58$ ); and the odds ratio of caring for parents/parents-in-law is almost double (odds ratio $=1.94$ ) for the provision of 20 hours or more of care per week to one's grandchildren.

The results presented in Tables 5 and 6 provide further evidence that the number of parents/parents-in-law is not associated with the care provision to younger grandchildren. However, the number of younger grandchildren appears to be negatively associated with care provision to one's parents/parents-in-law, suggesting that at higher levels of 'need' there may be a substitution effect. Not surprisingly, respondents are more likely to care for either generation if they co-reside with them. Sandwiched individuals who are currently married are more likely to care for younger grandchildren than those who are not married. However, the same pattern is not significant in terms of caring for one's parents/parents-in-law.

The likelihood of providing care is also associated with selected socio-economic characteristics. Compared with respondents living in rural areas, those living in urban areas are more likely to care for grandchildren but less likely to care for parents/parents-in-law. Respondents with a higher household wealth quintile index are more likely to provide care to either generation.

\section{Who amongst the sandwich generation is most likely to provide care to multiple generations?}

The results of the multinomial regression models of the probabilities of caring for grandchildren only, parent/parents-in-law only or neither generation, in 
Table 5. Odds ratios (OR) of providing care to grandchildren or parents/parents-in-law by whether respondent helped the other generation and by socio-demographic characteristics

\begin{tabular}{|c|c|c|c|c|}
\hline & \multicolumn{2}{|c|}{$\begin{array}{l}\text { Model 1: Caring } \\
\text { for grandchildren }\end{array}$} & \multicolumn{2}{|c|}{$\begin{array}{l}\text { Model 2: Caring } \\
\text { for parents/ } \\
\text { parents-in-law }\end{array}$} \\
\hline & OR & $p$ & OR & $p$ \\
\hline \multicolumn{5}{|l|}{ Caring provision (Ref. Not caring): } \\
\hline Caring for parents/in-law or grandchildren & 2.02 & 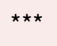 & 2.05 & 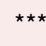 \\
\hline \multicolumn{5}{|l|}{ Age group (Ref. 45-49): } \\
\hline $50-54$ & 1.49 & $\star \star \star *$ & 0.95 & \\
\hline $55-59$ & 1.39 & ** & 1.01 & \\
\hline $60-64$ & 1.26 & & 0.98 & \\
\hline \multicolumn{5}{|l|}{ Gender (Ref. Male): } \\
\hline Female & 1.02 & & 1.11 & \\
\hline \multicolumn{5}{|l|}{ Marital status (Ref. Currently married): } \\
\hline Not currently married & 0.61 & * & 0.83 & \\
\hline \multicolumn{5}{|l|}{ Reporting chronic illness (Ref. No): } \\
\hline Yes & 1.02 & & 1.09 & \\
\hline \multicolumn{5}{|l|}{ Whether disabled (Ref. No): } \\
\hline Yes & 1.02 & & 1.12 & \\
\hline \multicolumn{5}{|l|}{ Number of parents/in-laws (Ref. 1): } \\
\hline 2 & 1.11 & & 1.24 & * \\
\hline 3 & 1.09 & & 1.05 & \\
\hline 4 & 1.02 & & 1.48 & \\
\hline \multicolumn{5}{|l|}{ Number of young grandchildren (Ref. 1): } \\
\hline 2 & 1.09 & & 0.83 & * \\
\hline 3 & 1.09 & & 0.88 & \\
\hline $4+$ & 1.16 & & 0.87 & \\
\hline \multicolumn{5}{|l|}{ Co-residence with grandchild(ren) (Ref. No): } \\
\hline Yes & 8.30 & 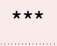 & 0.58 & 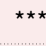 \\
\hline \multicolumn{5}{|l|}{ Co-residence with parents/in-laws (Ref. No): } \\
\hline Yes & 0.90 & & 3.88 & *** \\
\hline \multicolumn{5}{|l|}{ Working status (Ref. Not working): } \\
\hline Agricultural work & 1.13 & & 1.22 & \\
\hline Non-agricultural work & 0.88 & & 1.26 & \\
\hline \multicolumn{5}{|l|}{ Education (Ref. No schooling): } \\
\hline Primary school & 0.91 & & 0.94 & \\
\hline
\end{tabular}


Table 5. (Continued.)

\begin{tabular}{|c|c|c|c|c|}
\hline & \multicolumn{2}{|c|}{$\begin{array}{l}\text { Model 1: Caring } \\
\text { for grandchildren }\end{array}$} & \multicolumn{2}{|c|}{$\begin{array}{l}\text { Model 2: Caring } \\
\text { for parents/ } \\
\text { parents-in-law }\end{array}$} \\
\hline & OR & $p$ & OR & $p$ \\
\hline Secondary and above & 1.01 & & 1.23 & \\
\hline \multicolumn{5}{|l|}{ Urban/rural (Ref. Rural): } \\
\hline Urban & 1.58 & $\star \star \star *$ & 0.68 & ** \\
\hline \multicolumn{5}{|l|}{ Income (Ref. No): } \\
\hline Yes & 0.96 & & 1.14 & \\
\hline \multicolumn{5}{|c|}{ Household wealth quintile index (Ref. First): } \\
\hline Second & 1.01 & & 1.94 & * \\
\hline Third & 1.32 & * & 1.38 & *** \\
\hline Fourth & 1.33 & * & 1.67 & *** \\
\hline Fifth & 1.55 & ** & 1.84 & *** \\
\hline
\end{tabular}

Notes: $\mathrm{N}=3,980$. Ref.: reference category.

Source: Authors' own analysis, China Health and Retirement Longitudinal Study (CHARLS Wave 1).

Significance levels: ${ }^{*} p<0.05,{ }^{\star \star} p<0.01,{ }^{\star \star \star} p<0.001$.

comparison with caring for both generations (the reference category), are presented in Table 7. Co-residence plays an important role in determining informal care provision. Respondents are more likely to provide care only for younger grandchildren than for both generations if they are co-residing with grandchildren, or are not co-residing with parents/parents-in-law. Those not co-residing with parents/ parents-in-law nor younger grandchildren are more likely to be in the non-care provision group. Moreover, respondents living in urban areas are more likely to provide care only for younger grandchildren in comparison with caring for both generations. Those individuals in the sandwich generation who are in households in the lower household wealth quintile index are more likely to be in the non-care provision group.

\section{Discussion}

This analysis highlights that one-third of Chinese middle-aged (45-64) individuals are sandwiched between older parents/parents-in-law and young grandchildren, and thus face the possibility of providing informal care to both generations. However, amongst this sandwich generation, only 15 per cent are actually providing care to both generations at the same time. This percentage is relatively low in comparison with previous findings from some western societies (Grundy and Henretta, 2006; McGarrigle and Kenny, 2013). However, around 60 per cent of the sandwich generation are providing care to their younger grandchildren and the intensity of that care provision is high. This might be because younger grandchildren have greater everyday needs. The data show that more 'sandwiched' mid-life individuals 


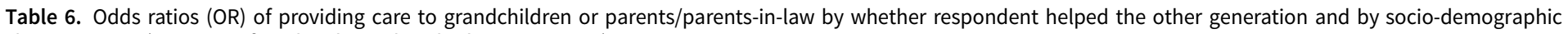
characteristics (estimate after the chained multiple imputations)

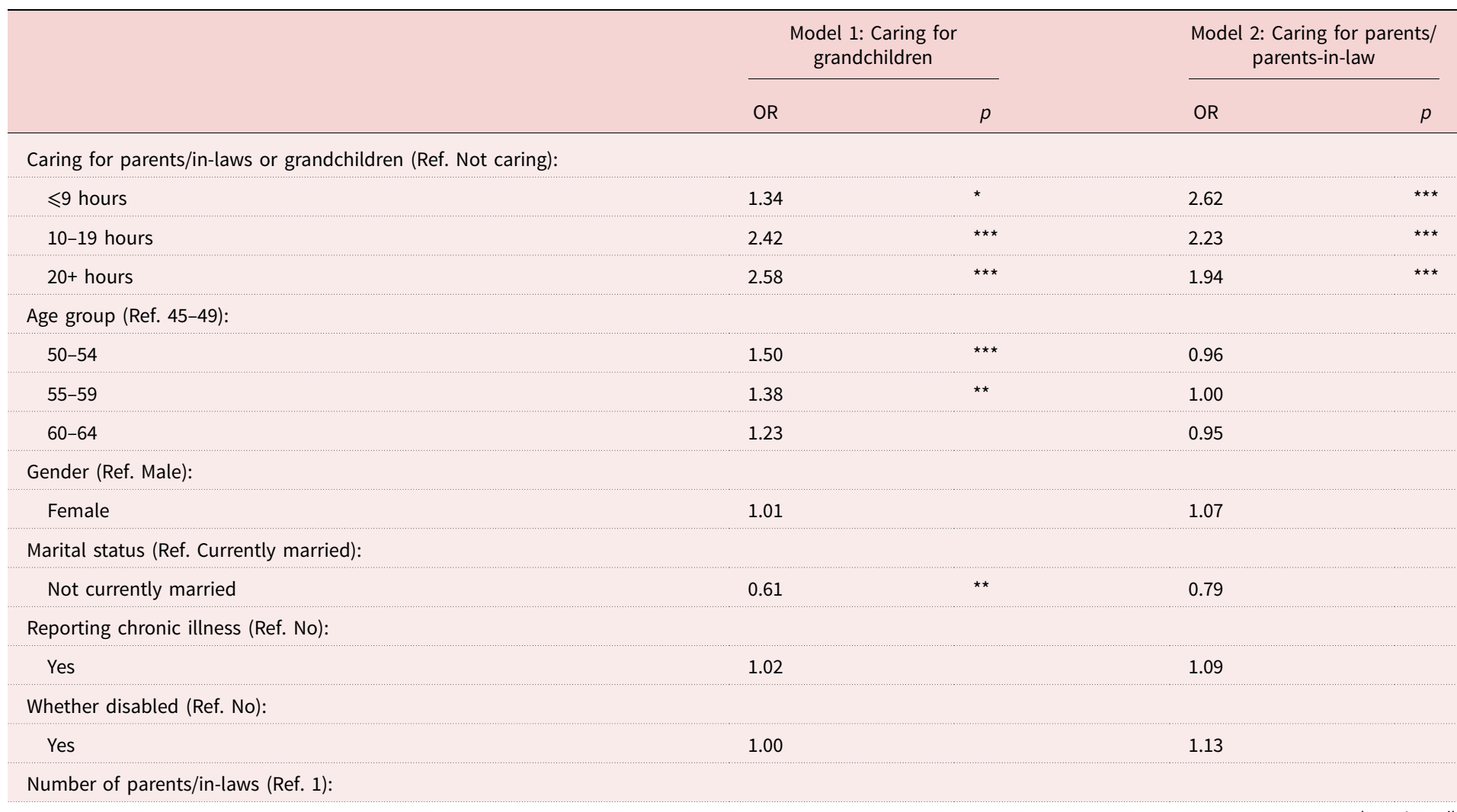


Table 6. (Continued.)

\begin{tabular}{|c|c|c|c|c|}
\hline & \multicolumn{2}{|c|}{$\begin{array}{l}\text { Model 1: Caring for } \\
\text { grandchildren }\end{array}$} & \multicolumn{2}{|c|}{$\begin{array}{c}\text { Model 2: Caring for parents/ } \\
\text { parents-in-law }\end{array}$} \\
\hline & OR & $p$ & OR & $p$ \\
\hline 2 & 1.11 & & 1.22 & * \\
\hline 3 & 1.11 & & 1.04 & \\
\hline 4 & 1.02 & & 1.42 & \\
\hline \multicolumn{5}{|c|}{ Number of young grandchildren (Ref. 1): } \\
\hline 2 & 1.09 & & 0.84 & \\
\hline 3 & 1.07 & & 0.90 & \\
\hline $4+$ & 1.16 & & 0.88 & \\
\hline \multicolumn{5}{|c|}{ Co-residence with grandchild(ren) (Ref. No): } \\
\hline Yes & 8.30 & $\star \star \star *$ & 0.57 & *** \\
\hline \multicolumn{5}{|c|}{ Co-residence with parents/in-laws (Ref. No): } \\
\hline Yes & 0.87 & & 3.85 & 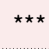 \\
\hline \multicolumn{5}{|c|}{ Working status (Ref. Not working): } \\
\hline Agricultural work & 1.13 & & 1.21 & \\
\hline Non-agricultural work & 0.89 & & 1.26 & \\
\hline \multicolumn{5}{|c|}{ Education (Ref. No schooling): } \\
\hline Primary school & 0.90 & & 0.92 & \\
\hline Secondary and above & 1.01 & & 1.20 & \\
\hline \multicolumn{5}{|l|}{ Urban/rural (Ref. Rural): } \\
\hline Urban & 1.54 & 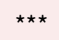 & 0.69 & $\star \star$ \\
\hline
\end{tabular}




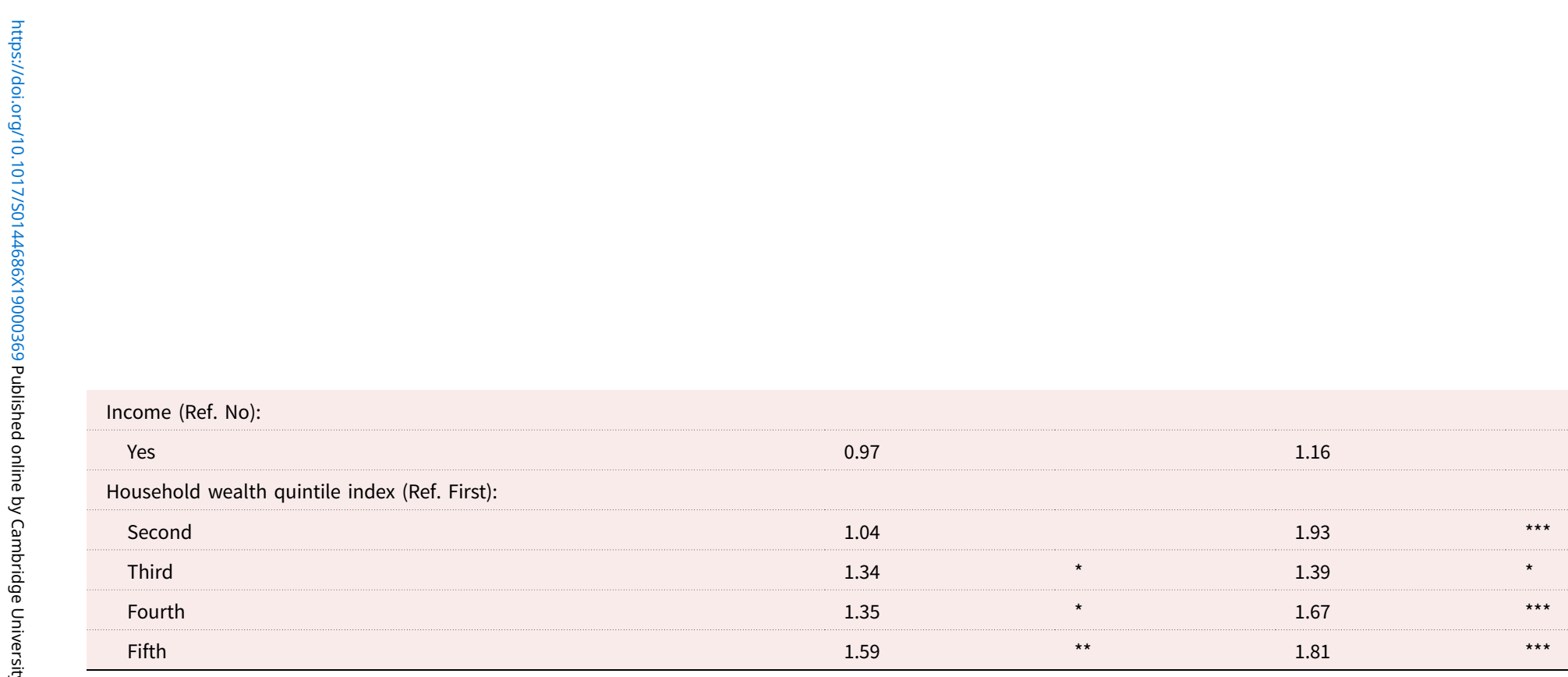

Notes: $\mathrm{N}$ (including imputed observations) $=4,031$. Ref.: reference category.

Source: Authors' own analysis, China Health and Retirement Longitudinal Study (CHARLS Wave 1).

significance levels: ${ }^{\star} p<0.05,{ }^{\star \star} p<0.01,{ }^{\star \star \star} p<0.001$. 
Table 7. Multinomial models: relative risk ratios (RRR) of people aged 45-64 helping only grandchildren, only parents/parents-in-law or neither generation relative to caring for both generations

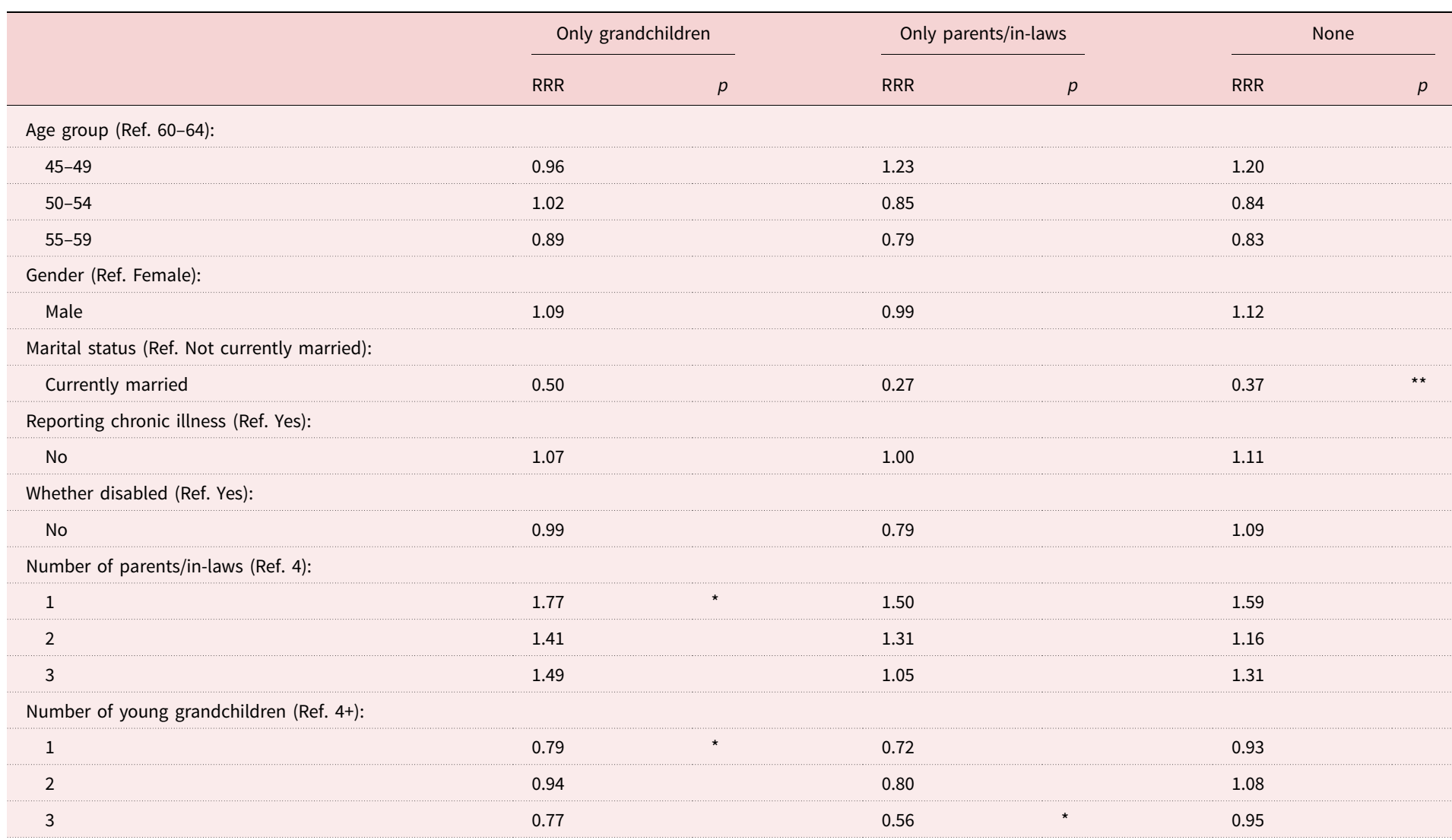




\begin{tabular}{|c|c|c|c|c|c|c|}
\hline No & 0.60 & $\star \star \star *$ & 8.35 & $\star \star \star \star$ & 4.96 & *** \\
\hline \multicolumn{7}{|c|}{ Co-residence with parents/in-laws (Ref. Yes): } \\
\hline No & 4.35 & $\star \star \star *$ & 1.10 & & 3.42 & *** \\
\hline \multicolumn{7}{|c|}{ Working status (Ref. Non-agricultural work): } \\
\hline Not working & 1.39 & & 1.12 & & 1.15 & \\
\hline Agricultural work & 1.14 & & 1.00 & & 0.82 & \\
\hline \multicolumn{7}{|c|}{ Education (Ref. Secondary and above): } \\
\hline No schooling & 1.24 & & 1.00 & & 1.24 & \\
\hline Primary school & 1.48 & ** & 1.42 & * & 1.55 & *** \\
\hline \multicolumn{7}{|c|}{ Urban/rural (Ref. Urban): } \\
\hline Rural & 0.61 & ** & 1.22 & & 1.03 & \\
\hline \multicolumn{7}{|l|}{ Income (Ref. Yes): } \\
\hline No & 1.02 & & 0.75 & & 1.04 & \\
\hline \multicolumn{7}{|c|}{ Household wealth quintile index (Ref. Fifth): } \\
\hline First & 1.37 & & 0.83 & & 2.43 & *** \\
\hline Second & 0.80 & & 1.07 & & 1.38 & \\
\hline Third & 1.50 & * & 1.45 & & 1.68 & ** \\
\hline Fourth & 1.06 & & 1.03 & & 1.28 & \\
\hline
\end{tabular}

Notes: $\mathrm{N}=3,980$. Ref.: reference category.

Source: Authors' own analysis, China Health and Retirement Longitudinal Study (CHARLS Wave 1).

Significance levels: ${ }^{*} p<0.05,{ }^{* \star} p<0.01,{ }^{* \star *} p<0.001$. 
provided informal care to their grandchildren than to their older parents/ parents-in-law, reflecting the fact that the study respondents were aged between 45 and 64, and thus many of their parents/parents-in-law (at least for the younger mid-lifers aged 45-54) were likely aged in their seventies or early eighties, and therefore still relatively healthy and without a need for care. A recent study in China found that the majority of older adults do not need care in daily life as a result of their improved health condition, on the contrary they may even play an important role in household chores or social activities (Du and Yang, 2010). Additionally, some of those older parents requiring support may be cared for by family members other than the respondents, such as the respondent's siblings or other extended family members, and/or institutional care services especially in urban areas. The flows of intergenerational exchange observed here support both the family adaptive strategy and family functional solidarity thesis.

Previous studies have found that grandparent involvement with grandchildren increases with the difficulty of the conditions that adult children are facing (Gibson, 2005). In contemporary China, unless there are significant improvements in the provision of formal care, it is likely that demands for informal care for younger grandchildren and to parents/parents-in-law will increase given the recently relaxed family planning policy allowing couples to have two children alongside continued improvements in life expectancy. Based on a recent report from the National Bureau of Statistics of PRC, in the two years following the implementation of the universal two-child policy in 2015, the number of new-born babies which were the second child increased by 1.6 million in 2017 compared with the same figure in 2016 ( $\mathrm{Li}, 2018)$. These 'extra' second parity babies are not evenly distributed across the country, with many of them likely to be born to parents living in urban areas, reflecting the fact that the previous family planning policy constrained all urban couples to one child, whilst in some rural areas second and even third births were allowed (Qin et al., 2018).

At the same time as demand is rising, the supply of informal care provision from grandparents is coming under pressure as the government is considering a major reform to increase the retirement age in the face of population ageing (Chen and Groenewold, 2017). If both mid-life women and men have to remain in the labour market for longer, fewer members of the sandwich generation will be available to provide informal care to either the younger or older generation. The potential decrease in supply allied with rising demand could put huge pressure on the supply of informal care provision. Previous research has found a negative association between demanding care-giving and health and wellbeing among the care-givers (McGarrigle and Kenny, 2013; Vlachantoni et al., 2013). In the long run, formal care as a complement to informal care as in many western societies (Dykstra and Fokkema, 2011) will be absolutely crucial to ease the pressure imposed on informal care (Zhan et al., 2006).

The results further show that providing care to one generation increases the chance of providing care to another generation. These findings are highly consistent with those in developed countries (Fingerman et al., 2010; Grundy and Henretta, 2006; Gomez-Leon et al., 2017) which support the 'solidarity hypothesis' against the 'competing demand hypothesis', with helping one generation being linked with helping another generation. However, an increasing number of younger 
grandchildren may have a negative impact on the care provision to parents/ parents-in-law, indicating somewhat competing explanations.

Co-residence plays an important role in terms of providing informal care to both generations. This 'residential propinquity' or 'residential solidarity' provides the opportunity for intergenerational exchange (Bengtson and Roberts, 1991). Under the norm of filial piety, younger people are expected to take care of their ageing parents through co-residential living (Li et al., 2005). Although over the past three decades, with housing improvement and the desire for independence among young generations, the number of nuclear households has been increasing (Hu and Peng, 2015), multigenerational living still persists, particularly when some family members are incapable of taking care of themselves (Chou, 2011). Previous research found a significant rise in co-residential living following widowhood and a deterioration in the functional health of older people in China (Zhang, 2004; Korinek et al., 2011). It is likely that such co-residence living arrangement transition would also occur to accommodate the informal care needs of younger grandchildren. Both phenomena reflect the family adaptive strategy to meet informal care needs.

Sandwiched individuals living in urban areas have a higher chance of providing care to younger grandchildren compared to providing care to both generations. This can be partially explained by the conflict between maternal work and child care. Women's labour force participation rates are very high in China due, in part, to the government's active promotion programmes in the past, and also due to women's key role of family breadwinner, but work arrangements are often not flexible, especially in urban areas. Unlike women in many western societies, who often use part-time work as a way to balance work and child-care demands (Evandrou and Glaser, 2002; Evandrou et al., 2002; Glaser et al., 2006), flexible work arrangements are generally not available in China (Chen et al., 2011). Meanwhile, public nurseries for age 0-3 are extremely rare (Corter et al., 2006). The majority of women in urban areas have to go back to work after maternity leave of three to six months after the birth, and leave the infant to be cared for by the grandparents.

This paper adds to the literature by examining the sandwich generation and their informal care provision to parents/parents-in-law and/or younger grandchildren, using a large nationally representative sample in China. To our knowledge, this is a first exploration of informal care provision amongst the sandwich generation in the Chinese context, although there is a growing literature on informal care to either older people or grandchildren. However, a number of limitations of this study should be borne in mind when interpreting the results. Firstly, the survey questions about care provision were asked in relation to the previous year, while questions about the respondents' living arrangements and other covariates referred to their current situations. Although most of the covariates might be consistent over the year, some might change after the care provision has occurred. Secondly, information regarding the need for support is not collected in the survey, which is essential for understanding the care provision and which shows a positive association with the provision of help in previous studies (Vlachantoni et al., 2011). Future studies may incorporate this measurement. Thirdly, the number of respondents with missing data on weekly hours of care for parents/in-laws and for 
grandchildren is considerable. One possible reason for this might be that such care is so integral to everyday life or so nuanced that many respondents may have found it challenging to recall how many weeks and hours per week they provided care to both older parents and grandchildren during the last year. Such a task might be even more difficult in cases of co-residence between the respondents and the care recipients. Recent studies have argued that there is room for improvement with recording such measurements, e.g. by prospectively using time diaries to collect care-giving frequency and intensity data (Chatzitheochari et al., 2017). In this study, the chained multiple imputations for the missing values relating to the intensity of care provision were carried out under the assumption that the missing values were missing at random, an assumption which is hard to meet. Nevertheless, comparison of the results with and without the multiple imputations indicate that the results regarding intensive informal care provision are consistent. Finally, given that caring for parents/parents-in-law increases the chance of caring for grandchildren, and vice versa, the two variables may be endogenous in the binary logistic regression models. Furthermore, unobserved factors such as a personal characteristic of a general caring feature or constraints might be related with both caring for one's older parents and for younger grandchildren. A future study aiming at the causal effect of care-giving to one generation on caring for another generation might address the potential endogeneity bias by using an instrumental variable approach (Coe and Van Houtven, 2009).

In conclusion, individuals within the sandwich generation in China make an important contribution to supporting two generations: their parents/parents-in-law and younger grandchildren. Although the proportion of such individuals providing care to both generations at the same time remains relatively low, the intensity of the care they provide is high. With population ageing proceeding at a rapid pace and with an increase in newborn second births in China following the updated family planning policies, the demand for intensive care to both generations will become even more relevant in the future. Going forward, more mid-lifers are likely to face the challenge of simultaneously caring for older parents/parents-in-law and young grandchildren, whilst also playing an active role in the labour market. As a result, there may be concerns about the potential stress or burden on future caregivers, and the resultant effects on their health and wellbeing. If the negative impact of increased multiple role occupancy on the health and wellbeing of midlife individuals is to be avoided or reduced, policy makers need to plan ahead in terms of the provision of formal care services for both older people and young children. More institutional alternatives and community-level or at-home services could be designed and implemented, offering additional options to families in need, so that, in the long run, the gap in the availability of social support between rural and urban areas is closed. In addition, co-residence plays a key role in care provision towards multiple generations, and such multi-generational living arrangements call for innovative house-building design which can be occupied either in separate, self-contained dwellings or through integrated living, depending on the preference of families and individuals. Ideally, a multi-sectoral approach is required, bringing together pre-school, education, housing, and health and social care services. 


\section{Note}

1 Multiple imputation using chained equations is a recognised technique for addressing missing data for more than one variable. It imputes multiple variables with missing values sequentially (normally from the variable with the least missing values to the variable with the most missing values). The chained equations approach is very flexible and can handle variables of different types such as continuous and binary (Azur et al., 2011). Once the data have been imputed, each imputed data-set (in this study we had ten data-sets) is 'complete' with no missing values. Analysing multiple imputed data includes two steps: (a) running a standard analysis (e.g. logistic regression) on each of the imputed data-sets, and (b) combining the estimates from each data-set to obtain the final result. The Stata version 15 command 'mi' was applied for the chained multiple imputations (StataCorp., 2017).

Author ORCIDs. (D) Athina Vlachantoni, 0000-0003-1539-3057.

Author contributions. All authors contributed to the conceptualisation, data analysis and writing.

Financial support. This work was supported by the Economic and Social Research Council Centre for Population Change (grant number ES/K007394/1); and the Economic and Social Research Council Global Challenges Research Fund Global Ageing and Long-term Care Network (GALNet) (grant number $\mathrm{ES} / \mathrm{P} 006779 / 1)$.

Conflict of interest. The authors declare no conflicts of interest.

Ethical standards. The study received ethical approval for using the secondary data from the Ethics Committee in the University of Southampton (21228).

\section{References}

Abramson TA (2015) Older adults: the 'panini sandwich' generation. Clinical Gerontologist 38, 251-267.

Azur MJ, Stuart EA, Frangakis C and Leaf PJ (2011) Multiple imputation by chained equations: what is it and how does it work? International Journal of Methods of Psychiatric Research 20, 40-9.

Bengtson VL and Roberts REL (1991) Intergenerational solidarity in aging families: an example of formal theory construction. Journal of Marriage and the Family 53, 856-870.

Chatzitheochari S, Fisher K, Gilbert E, Calderwood L, Huskinson T, Cleary A and Gershuny J (2017) Using new technologies for time diary data collection: instrument design and data quality findings from a mixed-mode pilot survey. Social Indicators Research 137, 379-390.

Chen A and Groenewold N (2017) An increase in the retirement age in China: the regional economic effects. Applied Economics 49, 702-721.

Chen F and Liu G (2012) The health implications of grandparents caring for grandchildren in China. Journals of Gerontology: Gerontology: Psychological Sciences and Social Sciences 67B, 99-112.

Chen F, Liu G and Mair CA (2011) Intergenerational ties in context: grandparents caring for grandchildren in China. Social Forces 90, 571-594.

Chou RJ (2011) Filial piety by contract? The emergence, implementation, and implications of the 'family support agreement' in China. Gerontologist 51, 3-16.

Coe NB and Van Houtven CH (2009) Caring for mom and neglecting yourself? The health effects of caring for an elderly parent. Health Economics 18, 991-1010.

Cong $\mathbf{Z}$ and Silverstein $\mathbf{M}$ (2012) Caring for grandchildren and intergenerational support in rural China: a gendered extended family perspective. Ageing \& Society 32, 425-450.

Corter C, Janmohammed Z, Zhang J and Bertrand J (2006) Selected issues concerning early childhood care and education in China. Paper commissioned for the EFA Global Monitoring Report 2007, Strong Foundations: Early Childhood Care and Education. Available at http://unesdoc.unesco.org/images/0014/ 001492/149200e.pdf.

Croll EJ (2006) The intergenerational contract in the changing Asian family. Oxford Development Studies 34, 473-491.

Du P and Yang H (2010) China's population ageing and active ageing. China Journal of Social Work 3, 139-152. 
Dykstra PA and Fokkema T (2011) Relationships between parents and their adult children: a West European typology of late-life families. Ageing \& Society 31, 545-569.

Elder GH (1998) The life course as developmental theory. Child Development 69, 1-12.

Evandrou M and Glaser K (2002) Changing economic and social roles: the experience of four cohorts of mid-life individuals in Britain, 1985-2000. Population Trends 110, 19-30.

Evandrou M, Glaser K and Henz U (2002) Multiple role occupancy in midlife: balancing work and family life in Britain. The Gerontologist 42, 781-789.

Fingerman KL, Pitzer LM, Chan W, Birditt K, Franks MM and Zarit S (2010) Who gets what and why? Help middle-aged adults provide to parents and grown children. Journals of Gerontology: Psychological Sciences and Social Sciences 66B, 87-98.

Friedman EM, Park SS and Wiemers EE (2015) New estimates of the sandwich generation in the 2013 panel study of income dynamics. The Gerontologist 57, 191-196.

Gibson PA (2005) Intergenerational parenting from the perspective of African American grandmothers. Family Relations 54, 280-297.

Glaser K, Evandrou M and Tomassini C (2006) Multiple role occupancy and social participation among midlife wives and husbands in the United Kingdom. International Journal of Aging and Human Development 63, 27-47.

Gomez-Leon M, Evandrou M, Falkingham J and Vlachantoni A (2017) The dynamics of social care and employment in mid-life. Ageing \& Society 39, 381-408.

Grundy E and Henretta JC (2006) Between elderly parents and adult children: a new look at the intergenerational care provided by the 'sandwich generation'. Ageing \& Society 26, 707-722.

Guo M, Aranda MP and Silverstein M (2009) The impact of out-migration on the inter-generational support and psychological wellbeing of older adults in rural China. Ageing \& Society 29, 1085-1104.

Hu B and Ma S (2018) Receipt of informal care in the Chinese older population. Ageing \& Society 38, 766793.

Hu Z and Peng XZ (2015) Household changes in contemporary China: an analysis based on the four recent censuses. Journal of Chinese Sociology 2, 1-20.

Korinek K, Zimmer Z and Gu D (2011) Transitions in marital status and functional health and patterns of intergenerational coresidence among China's elderly population. Journals of Gerontology: Psychological Sciences and Social Sciences 66B, 260-270.

Li L, Liang J, Toler A and Gu S (2005) Widowhood and depressive symptoms among older Chinese: do gender and source of support make a difference? Social Science and Medicine 60, 637-647.

Li XR (2018) Two Children Policy Effectiveness Continues to Show. Available at http://www.stats.gov.cn/tjsj/ sjjd/201801/t20180120_1575796.html. (In Chinese)

Lu JH and Wang XF (2013) Change of the marital status in Mainland China since 1990s. Social Sciences of Beijing 3, 62-72. (In Chinese)

McGarrigle C and Kenny RA (2013) Profile of the Sandwich Generation and Intergenerational Transfers in Ireland. Dublin: The Irish Longitudinal Study on Ageing.

Miller DA (1981) The 'sandwich' generation: adult children of the aging. Social Work 26, 419-423.

Moen P and Wethington E (1992) The concept of family adaptive strategies. Annual Review of Sociology 18, 233-251.

National Bureau of Statistics of PRC (2012) China Statistical Yearbook. Beijing: China Statistics Press. Available at http://www.stats.gov.cn/tjsj/ndsj/2012/indexeh.htm. (In Chinese)

National People's Congress of PRC (2004) The Constitution of the People's Republic of China. Beijing: State Council of People's Republic of China. Available at http:/www.gov.cn/gongbao/content/2004/content_62714.htm. (In Chinese)

National People's Congress of PRC (2013) The Law on Protection of the Rights and Interests of Older People of the People's Republic of China. Beijing: State Council of People's Republic of China. Available at http://www.gov.cn/flfg/2012-12/28/content_2305570.htm. (In Chinese)

Pierett CR (2006) The 'sandwich generation': women caring for parents and children. Monthly Labour Review 129, 3-9.

Qin M, Falkingham J and Padmadas S (2018) Unpacking the differential impact of family planning policies in China: analysis of parity progression ratios from retrospective birth history data, 1971-2005. Journal of Biosocial Science. Available online doi:10.1017/S002193201700061X. 
Rubin R and White-Means S (2009) Informal caregiving: dilemmas of sandwiched caregivers. Journal of Family and Economic Issues 30, 252-267.

Silverstein M, Gans D and Yang FM (2006) Intergenerational support of ageing parents - the role of norms and needs. Journal of Family Issues 27, 1068-1084.

StataCorp (2017) Stata: Release 15. Statistical Software. College Station, TX: StataCorp.

Vlachantoni A, Evandrou M, Falkingham J and Gomez-Leon M (2019) Caught in the middle in mid-life: provision of care across multiple generations. Ageing \& Society 1-21. Available online doi: 10.1017/ S0144686X19000047

Vlachantoni A, Evandrou M, Falkingham J and Robards J (2013) Informal care, health and mortality. Maturitas 74, 114-118.

Vlachantoni A, Shaw R, Willis R, Evandrou M, Falkingham J and Luff R (2011) Measuring unmet need for social care amongst older people. Population Trends 145, 60-76.

Yan YX (2003) Private Life Under Socialism: Love, Intimacy and Family Change in a Chinese Village, 19491999. Stanford, CA: Stanford University Press.

Zhan HJ, Liu G and Bai H (2006) Recent development in Chinese institutional elder care: changing concepts and attitudes. Journal of Aging and Social Policy 18, 85-108.

Zhang QF (2004) Economic transition and new patterns of parent-adult child coresidence in urban China. Journal of Marriage and Family 66, 1231-1245.

Zhao YH, Strauss J, Yang GH, Giles J, Hu PF, Hu YS, Lei XY, Liu M, Park A, Smith JP and Wang YF (2013) China Health and Retirement Longitudinal Study - 2011-2012 National Baseline Users' Guide. Available at http://charls.pku.edu.cn/uploads/document/2011-charlswave1/application/CHARLS_national baseline_users_guide.pdf.

Zimmer $\mathbf{Z}$ and Kwong J (2003) Family size and support of older adults in urban and rural China: current effects and future implications. Demography 40, 23-44.

Cite this article: Falkingham J, Evandrou M, Qin M, Vlachantoni A (2020). Informal care provision across multiple generations in China. Ageing \& Society 40, 1978-2005. https://doi.org/10.1017/ S0144686X19000369 